\title{
Discussões sobre o trabalho na aula de literatura a partir do poema Morte e Vida
}

\section{Severina}

\author{
Discussions about the work in the literature class from the poem Morte e Vida Severina \\ Discusiones sobre la obra en la clase de literatura del poema Morte e Vida Severina
}

Recebido: 04/11/2021 | Revisado: 15/11/2021 | Aceito: 17/12/2021 | Publicado: 22/12/2021

Mélody Hármony Bezerra da Costa
ORCID: https://orcid.org/0000-0003-4711-1296
Instituto Federal de Educação, Ciência e Tecnologia do Rio Grande do Norte, Brasil
E-mail: melody.costa @hotmail.com
Giann Mendes Ribeiro
ORCID: https://orcid.org/0000-0001-7628-3658
Instituto Federal de Educação, Ciência e Tecnologia do Rio Grande do Norte, Brasil
E-mail: giann.ribeiro@ifrn.edu.br

\begin{abstract}
Resumo
Esta pesquisa trata sobre o estudo do poema Morte e Vida Severina na perspectiva do trabalho e tem como objetivo apresentar uma sequência didática trabalhando o tema aqui abordado como forma de contribuir com o trabalho do professor de Literatura da Educação Profissional e Tecnológica. Como metodologia foi utilizada a pesquisa bibliográfica reunindo autores como Saviani (1994) e Sobral (et al, 2016), os quais discutem o trabalho como princípio educativo, e Dolz, Noverraz e Schneuwly (2004), os quais abordam a metodologia da sequência didática. Como resultados obteve-se uma sequência didática com três etapas desenvolvidas em quatro aulas as quais seguem uma proposta de apresentação, desenvolvimento e produção final a qual pode contribuir para um ensino de literatura reflexivo, abordando não apenas sobre o poema em si, mas sobre os desafios enfrentados no mundo do trabalho a partir dos problemas vividos pelo personagem Severino. Conclui-se que o planejamento para uma aula interdisciplinar requer tempo e dedicação, porém, é um esforço necessário quando se trata de buscar incluir na prática pedagógica um ensino fundamentado nos princípios da educação profissional e tecnológica.
\end{abstract}

Palavras-chave: Sequência didática; Trabalho; Educação profissional.

\begin{abstract}
This research deals with the study of the poem Morte e Vida Severina from the perspective of work and aims to present a didactic sequence working on the theme discussed here as a way to contribute to the work of the Literature teacher in Professional and Technological Education. As a methodology, bibliographic research was used, bringing together authors such as Saviani (1994) and Sobral (et al, 2016), who discuss work as an educational principle, and Dolz, Noverraz and Schneuwly (2004), who address the methodology of the didactic sequence. As a result, a didactic sequence was obtained with three steps developed in four classes which follow a proposal for presentation, development and final production which can contribute to a reflective teaching of literature, addressing not only the poem itself, but also the challenges faced in the world of work from the problems experienced by the character Severino. It is concluded that planning for an interdisciplinary class requires time and dedication, however, it is a necessary effort when it comes to seeking to include in the pedagogical practice a teaching based on the principles of professional and technological education.
\end{abstract}

Keywords: Didactic sequence; Work; Professional education.

\section{Resumen}

Esta investigación aborda el estudio del poema Morte e Vida Severina desde la perspectiva del trabajo y tiene como objetivo presentar una secuencia didáctica trabajando sobre el tema aquí discutido como una forma de contribuir a la labor del docente de Literatura en la Educación Profesional y Tecnológica. Como metodología se utilizó la investigación bibliográfica, reuniendo a autores como Saviani (1994) y Sobral (et al, 2016), que discuten el trabajo como principio educativo, y Dolz, Noverraz y Schneuwly (2004), que abordan la metodología de la secuencia didáctica. Los resultados obtuvieron una secuencia didáctica con tres pasos desarrollados en cuatro clases que siguen una propuesta de presentación, desarrollo y producción final que puede contribuir a una enseñanza reflexiva de la literatura, abordando no solo el poema en sí, sino también los desafíos que se enfrentan en el mundo de la literatura. trabajar a partir de los problemas vividos por el personaje Severino. Se concluye que planificar una clase interdisciplinaria requiere tiempo y dedicación, sin embargo, es un esfuerzo necesario a la hora de buscar incluir en la práctica pedagógica una enseñanza basada en los principios de la educación profesional y tecnológica.

Palabras clave: Secuencia didáctica; Trabaja; Educación profesional. 


\section{Introdução}

A Educação Profissional e Tecnológica (EPT) tem suas diretrizes fundamentadas em uma educação para a formação humana integral, tendo por base o mundo do trabalho, como bem afirma Pacheco (2015). Assim, a prática pedagógica do professor requer um trabalho que envolva interdisciplinaridade e transversalidade para que possa contemplar elementos para um desenvolvimento completa dos sujeitos. Neste sentido, esta pesquisa propõe uma sequência didática que poderá contribuir para as aulas de literatura no senti de adotar a problemática do trabalho de forma transversal.

Ter o trabalho como um princípio educativo é um desafio para muitos docentes da EPT que buscam, em seu cotidiano, formas de trazer essa temática para o âmbito de suas disciplinas na tentativa de superar o modelo dicotômico de ciência/tecnologia e teoria/prática e com isso contribuir para romper com modelos educacionais que insistem em manter de forma fragmentada o conhecimento das áreas do saber. Neste sentido, refletir sobre o trabalho a partir de um estudo literário pode ser uma contribuição na busca desta superação.

Este artigo é parte da dissertação de mestrado em Educação Profissional e Tecnológica do Instituto Federal de Educação, Ciência e Tecnologia do Rio Grande do Norte (IFRN), a qual tem como título "O estudo do poema Morte e Vida Severina a partir da perspectiva do trabalho" e traz como problema a questão de como abordar o tema trabalho a partir de uma análise literária do poema Morte e Vida Severina escrito entre os anos de 195431955 pelo autor João Cabral de Melo Neto

Os objetivos deste artigo é abordar conceitos importantes para a EPT, como educação e trabalho e, especialmente, apresentar uma sequência didática indicando uma proposta de análise do poema Morte e Vida Severina, abordando a temática trabalho a partir das perspectivas e problemas vivenciados pelo personagem Severino.

\section{Metodologia}

Como atividade complexa e sistematizada, toda pesquisa acadêmica demanda planejamento, o que, em sua dimensão mais ampla, chama-se de delineamento. Este envolve os “[...] fundamentos metodológicos, a definição dos objetivos, o ambiente da pesquisa e a determinação das técnicas de coleta e análise de dados" (Gil, 2010, p 29). Assim, na busca pelo método mais adequado para a realização desta pesquisa, utilizar-se-á, quanto a procedimentos, a pesquisa bibliográfica, tendo atentado para as particularidades oferecidas por essa metodologia.

Quanto à abordagem, pode-se afirmar que a pesquisa é do tipo qualitativa, pois entende-se que esse método possibilita uma melhor análise dos autores abordados, tendo em vista que se buscou uma melhor compreensão dos aspectos observados. Desse modo,

Partindo do princípio de que o ato de compreender está ligado ao universo existencial humano, as abordagens qualitativas não se preocupam em fixar leis para se produzir generalizações. Os dados da pesquisa qualitativa objetivam uma compreensão profunda de certos fenómenos sociais apoiados no pressuposto da maior relevância do aspecto subjetivo da ação social. Contrapõem-se, assim, à incapacidade da estatística de dar conta dos fenómenos complexos e da singularidade dos fenómenos que não podem ser identificados através de questionários padronizados (Goldenberg, 2009, p. 49).

Assim, esta pesquisa buscou analisar e compreender seus resultados a partir da análise de referências como Saviani (1994) e Sobral (et al, 2016), que discutem o trabalho enquanto princípio educativo diante das novas tecnologias, Frigoto (2002), que aborda o conhecimento e a educação do trabalhador e Ciavatta (2006), que trata da questão da formação do cidadão emancipado.

Além disso, também foram pesquisados autores que discutem o processo de construção da sequência didática como, por exemplo, Dolz et al. (2004), os quais apresentam um procedimento que fundamenta a sequência apresentada nesta pesquisa. 


\section{Resultados e Discussão}

\subsection{O trabalho enquanto princípio educativo}

Para uma melhor compreensão sobre o trabalho como princípio educativo, é importante ter-se o conhecimento mais aprofundado sobre a história, tendo como ponto de partida algumas discussões que contribuíram significativamente para a EPT. Nesse sentido, é importante aqui destacar o filósofo italiano Antônio Gramsci, que defendia a escola unitária, a qual se fundamentaria a partir de uma relação entre o trabalho intelectual e o industrial. De acordo com o autor,

A escola unitária ou de formação humanista (entendido este termo, "humanismo", em sentido amplo e não apenas em sentido tradicional), ou de cultura geral, deveria assumir a tarefa de inserir os jovens na atividade social, depois de têlos elevado a um certo grau de maturidade e capacidade para a criação intelectual e prática e a uma certa autonomia na orientação e na iniciativa (Gramsci, 2001, p. 36).

Ou seja, Gramsci (2001) defendia que a escola deveria oferecer uma formação tanto intelectual quanto prática, na tentativa de acabar com o modelo puramente capitalista, que dividia a educação para grupos sociais distintos.

Nesse sentido, é importante destacar que essa discussão trazida pelo autor, apesar de haver-se dado no início da década de 1930, é bastante atual, tendo em vista os problemas encontrados nas escolas atuais, que são, segundo Sobral (et al, 2016), guiadas pela lógica do capitalismo. No entanto, os autores afirmam a importância de uma escola que, além de oferecer ao mundo do trabalho um profissional qualificado, também garanta a aprendizagem humanizada de que o aluno precisa.

Não se pode barrar ou mesmo negar o desenvolvimento industrial de uma nação. No entanto, é preciso criar e desenvolver instituições que ofereçam à sociedade uma formação integral, a qual qualifique o aluno para o trabalho técnico e, ao mesmo tempo, seja humanista, intelectual. Conforme os autores,

[...] surge a necessidade de modificar o processo de formação dessa cisão que ocorre entre essas duas categorias distintas, que consiste em formar o técnico político, superando a sua falta de entendimento das questões que regem a administração do processo produtivo, e, por outro lado, formar funcionário especialistas que sejam capazes de deliberar, tomar decisões acerca de questões políticas (Sobral, et al, 2016, p. 184).

Nesse sentido, Sobral (et al, 2016) defendem uma escola capaz de oferecer uma formação omnilateral, que permita ao trabalhador ter consciência do processo produtivo, além do conhecimento técnico especializado para realizar determinada atividade.

Medeiros Neta, Assis e Lima (2016) entendem que o trabalho está ligado à educação de maneira ontológica, tendo em vista que ambos fazem parte da condição humana. No entanto, ainda hoje há o problema da dualidade educacional, que insiste em dissociar o trabalho intelectual do trabalho mecânico. Desse modo, "o que deveria ser uma prática humanizadora, nos padrões capitalistas de produção, se tornou um mecanismo de exploração, alienação e desumanização" (Medeiros Neta; Assis; Lima, 2016, p. 108).

De acordo com Medeiros Neta et al., (2016, p. 108), o trabalho sempre possibilitou aprendizagens ao ser humano. No entanto, foi a partir de Karl Marx que passou a ser pensado como um princípio educativo. Nesse sentido, segundo as autoras, a educação para o trabalho objetiva "a inclusão social, laboral e política dos sujeitos, numa perspectiva integrada" (Medeiros Neta et al., 2016, p. 108). Nesse sentido, sendo o trabalho e a educação partes integrantes da vida do ser humano, é essencial que se estabeleçam de forma integrada e integrante.

A ideia de que educação se contrapõe a trabalho ainda hoje é muito presente. Saviani (1994) aponta que a tendência que ainda predomina é a de que a educação é o não-trabalho, ou seja, a educação permanece como um bem de consumo, improdutivo. No entanto, o autor considera que, diante de todo o processo histórico de escolarização e de educação em espaços 
escolares e não escolares, o trabalho "foi, é e continuará sendo princípio educativo do sistema de ensino em seu conjunto" (Saviani, 1994, p. 13).

Para Saviani (1994), o trabalho é quem determina o surgimento da escola desde sua base primária. Esse autor reconhece ainda que a escola é uma das formas de educar, embora não seja a única, muito menos a principal. Dessa forma, pode-se aqui fazer uma relação entre todo o contexto vivenciado pelo personagem Severino, do poema Morte e Vida Severina, tendo em vista que ele enfrenta vários desafios em sua peregrinação e, apesar de não se mencionar uma educação escolar, formal, o retirante aprende e ensina sobre a vida, sobre a natureza, sobre o trabalho e sobre a sociedade de sua época (década de 1950).

Saviani (1989) considera ainda que a educação é um instrumento de luta hegemônica, parte do instrumento de transformação social, mesmo que de forma secundária. Para o autor,

Luta hegemônica significa precisamente: processo de desarticulação-rearticulção, isto é, trata-se de desarticular dos interesses dominantes aqueles elementos que estão articulados em torno deles, mas não são inerentes à ideologia dominante e rearticulá-los em torno dos interesses populares, dando-lhes a consistência, a coesão e a coerência de uma concepção de mundo elaborada, vale dizer de uma filosofia. Considerando-se que toda relação de hegemonia é necessariamente uma relação pedagógica, cabe entender a educação como um instrumento de luta. Luta para estabelecer uma nova relação hegemônica que permita constituir um novo bloco histórico sob a direção da classe fundamental dominada da sociedade capitalista - o proletariado. Mas o proletariado não pode se erigir em força hegemônica sem a elevação do nível cultural das massas. Destaca-se aqui a importância fundamental da educação (Saviani, 1989, p. 10-11).

Dessa forma, essa luta hegemônica defendida por Saviani (1989) possibilita às classes populares a mudança de pensamento, a consciência de classe e a "passagem da condição de 'classe em si' para a condição de 'classe para si'" (Saviani, 1989, p. 11). Essa conscientização levaria o proletariado a ter influência expressa nos processos educativos e, a este último, seria resgatado o papel primordial do trabalho como princípio educativo, pois é ele que embasa as lutas das classes populares.

Venzel (2007) afirma que a sociedade não existe sem homem e o homem não existe sem o trabalho. Para a autora, o trabalho proporciona à sociedade, além das relações sociais que se estabelecem a partir dele, a produção das condições materiais e expeditivas para a existência humana. É por meio do trabalho que o homem se relaciona com a natureza, tornando o mundo mais humano.

Apesar de demonstrar a importância do trabalho para a sociedade, de forma geral e para a vida do ser humano, Venzel (2007) também demonstra que ele foi (e ainda é) utilizado como instrumento de alienação e dominação. De alienação, porque a autora considera que uma das principais características para tal fator é a fragmentação e a mecanização das tarefas.

No início, quando o trabalhador dominava e controlava todo o processo de produção do material e produto, o homem era mais realizado e liberto. Hoje, o trabalho qualificado foi reservado para poucos, principalmente para os que dominam a ciência e a tecnologia e aos demais foi reservada a desqualificação, pois estes não dominam a técnica e a ciência, não conhecem todo o processo de produção e foi renegado a executar tarefas simples e repetitivas. Neste tipo de organização, o trabalho foi automatizado, destruiu o trabalho qualificado, o trabalho intelectual do operário, a iniciativa do trabalhador, a liberdade de expressão que é controlada por um gerente que distribui as funções da mais complexa para a mais simples (Venzel, 2007, p. 5).

Desse modo, Venzel (2007) considera que a alienação pelo trabalho se dá principalmente pelo despreparo e pela desqualificação. Assim, pode-se considerar que a escola profissional, fundamentada em uma educação libertadora, não só qualifica para o trabalho, mas também o torna desalienante, proporcionando ao trabalhador uma formação humana e, com esta, todas essas condições intelectuais de liberdade de expressão e de inciativa mencionadas pela autora. 
Medeiros Neta et al., (2016) chamam atenção para o desafio que é formar o aluno de maneira integral, com base nos ensinos propedêutico e profissionalizante. Para as autoras, a existência formal de um Ensino Médio Integrado, por exemplo, não oferece garantias de que a educação ocorrerá, de fato, de forma integrada e integral, com articulação dos núcleos estruturante, articulador e tecnológico. Para as autoras, é necessário que haja um diálogo constante entre esses três núcleos para que, de fato, exista uma formação que contemple as dimensões de trabalho, ciência, cultura e tecnologia, que devem subsidiar a formação humana.

Deste modo, a integração do ensino médio à educação profissional exige práticas educativas problematizadoras, que permitam aos educandos perceberem-se enquanto sujeitos sociais, capazes de compreender as relações de trabalho nas quais estão ou estarão inseridos, promovendo um diálogo entre os conhecimentos de cunho prático-profissional e os conhecimentos culturais e científicos (Medeiros Neta et al., 2016, p. 111-112).

Dessa forma, integrar os conteúdos sistematizados das disciplinas à problematizações do cotidiano é uma das formas de se ter um uma educação integrada, pois esse modo apresentado por Medeiros Neta et al., (2016), de uma relação dialógica entre conhecimentos profissionais, culturais e científicos, pode levar o educando a uma formação integral.

Tavares e Corso (2015) entendem que o mundo do trabalho é um grande desafio para os jovens, os quais, muitas vezes, ingressam no mercado sem ter seus direitos trabalhistas garantidos. Essa exploração provoca na sociedade um aumento da desigualdade. Dessa forma, uma formação que tem como princípio educativo o trabalho pode contribuir para superar esse tipo de relação. Dessa forma, "o trabalho como princípio educativo propicia uma compreensão do processo histórico de produção científica e tecnológica, conhecimentos que apropriados e desenvolvidos contribuem para transformar as condições de vida" (Tavares \& Corso, 2015, p. 52).

Sobre as mudanças que uma educação profissional pode causar na vida dos sujeitos e na sociedade, Frigotto (2002) salienta que ela pode superar a visão utilitarista do trabalho, sendo um processo de buscar transformar as relações sociais no trabalho que, para o autor, são desumanizadoras e deseducativas:

A consciência crítica é o primeiro elemento deste processo que permite perceber que é dentro destas velhas e adversas relações sociais que podemos construir outras relações, onde o trabalho se torne manifestação de vida e, portanto, educativo (Frigotto, 2002, p.14).

Dito de outra forma, a educação pelo trabalho e para o trabalho forma o sujeito para a vida, de modo que o trabalhador torna-se consciente para exercer sua autonomia tanto por meio do trabalho, quanto neste, transformando as relações trabalhistas e, principalmente, contribuindo para a diminuição da exploração e das desigualdades.

Sabe-se, no entanto, que essa educação emancipadora apresentada por vários autores que defendem a educação unitária, politécnica, integral, não é a educação que o capitalismo deseja. De acordo com Ciavatta (2006), há duas lógicas distintas entre trabalho e educação:

Há uma contradição entre a lógica da produção capitalista e a lógica da educação. A primeira tem base no lucro, na exploração do trabalho, no tempo breve em que deve se realizar a atividade produtiva, no corte de custos, no aumento da produtividade do trabalho, na competitividade, na mercantilização de toda produção humana. A segunda lógica tem a finalidade de formar o ser humano e deve pautar-se pela socialização do conhecimento, o diálogo, a discussão, o tempo médio e longo da aprendizagem, a humanização, a emancipação das amarras da opressão, o reconhecimento das necessidades do outro, o respeito à sua individualidade, a participação construtiva e a defesa dos direitos de cidadania (Ciavatta, 2006, p. 79-80). 
Dessa forma, Ciavatta (2006) observa certo desafio em se estabelecer a educação para o mundo do trabalho, pois, como a autora apresentou, são lógicas diferenciadas. Assim, a educação profissional tem diante de si um desafio complexo de barrar essa exploração da mão de obra humana, cujo combate constitui, há décadas, uma luta das classes trabalhadoras.

Nesse sentido, Ciavatta (2006) defende a ideia de emancipação do cidadão produtivo, entendendo-a no sentido de torná-lo livre, independente e produtivo, ou seja, aquele capaz de inserir-se na sociedade mediante o trabalho. Desse modo,

Mesmo dentro de uma sociedade capitalista, que nos parece que uma educação assim sinaliza aspectos emancipatórios importantes. Trata-se de dar aos jovens estudantes uma leitura ampliada do mundo e uma preparação crítica, intelectual e profissional, para atuar e obter meios de vida, mesmo em um mundo onde crescem o desemprego, a desregulamentação das relações de trabalho, o empobrecimento de grandes massas da população (Ciavatta, 2006, p. 88-89).

Nessa perspectiva, Ciavatta (2006) entende que a educação profissional integra a educação geral com a formação específica, superando a hierarquia das classes sociais e contribuindo para o processo emancipatório de trabalhadores.

Souza (2014) afirma que a Educação Profissional prepara os jovens para o mundo do trabalho, mas também para uma formação humana. Para o autor, "o trabalho é percebido como parte do processo de formação e de realização humana". Dessa forma, não se deve pensar em trabalho apenas como uma prática econômica, mas como um princípio educativo que se relaciona com outros aspectos da formação humana, fazendo parte de um conjunto de fatores que favorecem o processo educativo.

Ele é a ação humana de interação com a realidade para a satisfação de necessidades e produção de liberdade. Nesse sentido, trabalho não é emprego, mas produção, criação, realização humanas. Compreender o trabalho nessa perspectiva é compreender a história da humanidade, as suas lutas e conquistas mediadas pelo conhecimento humano. (Souza, 2014, p. 6).

Não se pode negar que o modelo capitalista precisa de profissionais qualificados para assumir o trabalho técnico. Porém, isso não pode significar que esses trabalhadores não devam ter, também, uma formação humana, intelectual e emancipatória.

Desse modo, a educação profissional e tecnológica surgiu como uma opção para qualificar essa mão de obra, ao mesmo tempo que oferece uma educação geral, ou integral. É nesse tipo de educação que, segundo Fischer e Franzoi (2009), o trabalho adquire um lugar de dignidade, "porque é aí que as vivências de trabalho circulam/podem circular com todo o seu vigor, com a sua força de princípio educativo no âmbito político-pedagógico na escola" (Fischer \& Franzoi, 2009, p. 41).

Fígaro (2008) entende que o trabalho é uma atividade por meio da qual se cria algo para si ou para o outro. Já o mundo do trabalho é algo mais complexo de se definir, sendo conceituado pela autora como

[...] conjunto de fatores que engloba e coloca em relação a atividade humana de trabalho, o meio ambiente em que se dá a atividade, as prescrições e as normas que regulam tais relações, os produtos delas advindos, os discursos que são intercambiados nesse processo, as técnicas e as tecnologias que facilitam e dão base para que a atividade humana de trabalho se desenvolva, as culturas, as identidades, as subjetividades e as relações de comunicação construídas nesse processo dialético e dinâmico de atividade (Fígaro, 2008, p. 92).

Assim, o mundo do trabalho é muito mais amplo que o mercado de trabalho, sendo importante conhecer essas dimensões, tendo em vista que este trabalho visa proporcionar uma discussão a respeito dessa complexidade, abordando questões sobre o mercado, porém, no âmbito complexo e dinâmico que é o conjunto de elementos que constituem a concepção de mundo do trabalho. E é a partir de tal entendimento que se tem subsídios para desenvolver abordagens no ensino da Literatura, sob a ótica do trabalho. 
Oliveira Neto et al., (2018), compreendem que na atualidade muitas vezes o trabalho é visto como algo penoso e esse pensamento implica na concepção que se pode ter do trabalho enquanto um princípio educativo. Esta ideologia pode está relacionada a mentalidade de que, historicamente, o trabalho era coisa de escravos, principalmente em decorrência da tardia abolição da escravatura no Brasil. Outro fator que tem contribuído para essa visão, segundo os autores, é a perspectiva apresentada pela religião de que o trabalho seria algo relacionado a castigo. "Com tais considerações, fica evidente que há dificuldades com relação ao entendimento do conceito da categoria trabalho, bem como a necessidade de entendê-lo corretamente" (Oliveira Neto et al., 2018, p. 46).

Para uma melhor compreensão do termo trabalho e, especialmente, o entendimento de trabalho enquanto princípio educativo, Oliveira Neto et al., (2018), buscam uma definição ontológica e outra histórica. Na primeira, os autores consideram ser um sentido "permanente e imutável". Neste sentido:

[...] fica evidente que a categoria trabalho considerada em seu sentido ontológico, ou seja, como parte inerente ao ser dos homens, é a condição necessária para sua sobrevivência e subsistência. Além disso, é uma condição permanente, existirá enquanto o homem existir (Oliveira Neto et al., 2018, p. 47).

Assim, o sentido ontológico do trabalho diz respeito, segundo Oliveira Neto et al., (2018), a sua natureza intrínseca ao ser humano, pois, este é obrigado a realizar o trabalho para viver, para manter-se vivo. O ser humano precisa criar condições para conseguir sobreviver e viver em meio a natureza e sociedade, neste sentido, o trabalho possibilita que ele construa essas condições transformando a natureza, adaptando-a as suas necessidades. É nesse sentido que o trabalho faz parte da própria existência do homem. Já o sentido histórico os autores definem da seguinte forma:

Enquanto o primeiro sentido recebe sua definição pelo fato de ser impossível a existência e sobrevivência do homem sem a mediação do trabalho entre si e a natureza, o segundo sentido vem explicar a forma como acontece essa mediação, e essas formas, esses modos, mudam de acordo com a organização social nos diferentes períodos da história. Nos dias de hoje, por exemplo, essa forma é o trabalho assalariado (Oliveira Neto et al., 2018, p. 48).

Deste modo, o sentido histórico do trabalho é o que muda no decorrer do tempo, conforme cada contexto social existente. Ou seja, depende das mudanças e transformações das relações sociais do trabalho e sua organização. Ou seja, cada período histórico o trabalho teve concepções e percepções diferenciadas que vão se moldando à sociedade de cada época.

Para Maciel (2018), na sociedade atual, sob o regime capitalista, as experiências do trabalho enquanto princípio educativo foram raras e tiveram poucas análises em relação. Porém, o autor compreende que o trabalho atende os fundamentos pedagógicos no sentido da natureza filosófica relacionada a concepção de homem e o de natureza epistemológica, que diz respeito a concepção de educação, porém, carece de uma terceira, e importante, concepção que é a de natureza metodológica. Porém, concepção marxiana viria a preencher essa lacuna:

Parece objetivo que esta concepção se sustenta sobre três alicerces: o intelectual, que é formado pela aquisição do conhecimento científico e cultural; o corporal, enquanto desenvolvimento físico; e, o tecnológico, enquanto domínio de princípios gerais necessários ao manejo dos diversos ramos industriais. O problema é que, na sequência do raciocínio, após reafirmar a importância da indissociabilidade entre educação intelectual, educação corporal e educação tecnológica, Marx (1976, p. 179) substitui o termo technologique por polytechnique [...] (Maciel, 2018, p. $88)$.

Ou seja, a politecnia é a forma que vem a suprir a necessidade metodológica das concepções de trabalho enquanto princípio educativo. É uma forma, segundo Maciel (2018), de operacionalizar o trabalho enquanto princípio educativo. Ou seja, a natureza pedagógica que sustenta a concepção educativa do trabalho é a politecnia. 
Compreendendo esse contexto atual de trabalho e educação é importante que seja trabalhado nas salas de aula da educação profissional e tecnológica, buscando abordar as concepções e trabalho no âmbito das mais diversas disciplinas. Assim, o desenvolvimento de uma sequência didática capaz de direcionar o aluno a fazer reflexões sobre tais conceitos é de grande importância. No entanto, para melhor conhecer como se dá tal atividade é preciso conhecer sobre o que se trata uma sequência didática e sua composição metodológica.

\subsection{Sequência didática: conceituação}

Para melhor embasamento do produto educacional (PE) desenvolvido nesta pesquisa, é importante o conhecimento sobre sequência didática (SD). Nesse sentido, de acordo com Dolz et al., (2004, p.96), "Uma 'sequência didática' é um conjunto de atividades escolares organizadas, de maneira sistemática, em torno de um gênero textual oral ou escrito." Para melhor exemplificar esse conceito, os autores apresentam o esquema a seguir:

Figura 1 - Esquema de sequência didática.

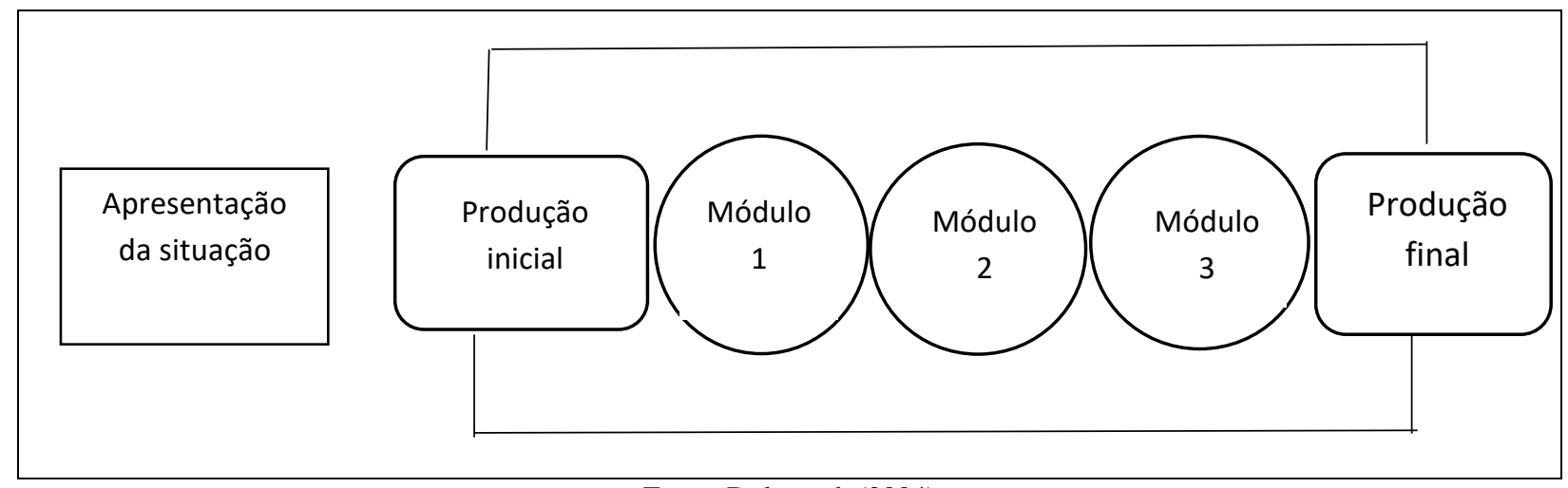

Fonte: Dolz et al. (2004)

Verifica-se, portanto, que a sequência didática é dividida em quatro fases. A primeira diz respeito à Apresentação da situação, que propõe uma apresentação detalhada das atividades que serão realizadas, de seus objetivos e dos principais aspectos do gênero que será trabalhado. Nessa apresentação, o aluno tem acesso ao gênero, descobrindo seus principais aspectos e os meios de produção e divulgação. A segunda fase é a Produção inicial, a qual pode ser realizada em equipe ou individualmente e pretende possibilitar a identificação do conhecimento prévio dos alunos acerca do que será estudado. Essa avaliação será o ponto de partida para o planejamento das futuras atividades, que será adaptável, respeitando o ritmo de aprendizagem dos alunos. A terceira fase corresponde aos Módulos, que são constituídos de atividades que possibilitam o domínio do conteúdo proposto, pois cada aspecto deve ser trabalhado de maneira aprofundada. No caso do gênero textual, é preciso desenvolver metodologias que contemplem: o conteúdo temático, a situação comunicativa, a forma composicional, as marcas linguísticas próprias do gênero. De acordo com as dificuldades apresentadas, o professor pode adequar suas aulas em função dos conteúdos que demandam maior atenção.

A quarta e última fase é a Produção final, que corresponde aos resultados da sequência. Esse momento torna-se uma espécie de parâmetro para avaliar os conhecimentos adquiridos no processo da sequência didática. Além disso, fornece ao aluno a observância de seu comportamento quanto à produção de um texto. De acordo com Dolz et al., (2004), os alunos podem realizar uma produção consistente com base nos conteúdos trabalhados durante os módulos. Para os autores, toda a proposta de intervenção deve ser fixada em um contexto no qual os alunos encontrem um sentido para desenvolver essa produção e em que se manifestem as esferas de circulação do gênero. 
Para Araújo (2013, p. 323), a sequência didática é uma forma ou um modelo que o docente utiliza para "organizar atividades de ensino em função de núcleos temáticos e procedimentais", visando proporcionar ao aluno o melhor conhecimento sobre o gênero textual estudado, bem como sobre as situações de comunicação estabelecidas. De tal modo, a produção inicial, os módulos e a produção final estabelecidos em uma sequência didática devem ser progressivos, ou seja, os alunos são apresentados a situações graduais de aprendizagem e, chegando à etapa final, a última produção é um ponto crucial para que o professor lhes avalie o progresso.

Segundo Araújo (2013), o modelo idealizado por Dolz et al., (2004) foi criado a partir de suas experiências em escolas de Genebra. Portanto, quando adotado em nossa realidade, deve ser adaptado. Desse modo, a escolha pelo gênero textual poema e, mais especificamente, pelo poema Morte e vida Severina, de João Cabral de Melo Neto, teve como critério o fato de se tratar de um poema que revela vários aspectos de um povo, como a questão do trabalho, o qual é ponto de partida deste estudo, tendo em vista que será direcionado a alunos da rede de educação profissional e tecnológica.

Entende-se que trabalhar com gêneros textuais, de acordo com Brocardo e Costa-Hübes (2010, p. 2), apresenta as funções de "fazer rir, fazer chorar, informar, orientar, persuadir, etc.". Assim, o poema escolhido para esta pesquisa tem o propósito de orientar e fazer o aluno refletir sobre as dificuldades enfrentadas no mundo do trabalho. Para os autores, "os textos podem ser compreendidos como a materialidade do discurso de determinada esfera da atividade humana que, para fazerse presente socialmente, elabora seus enunciados de maneira 'relativamente estável'” (Brocardo \& Costa-Hübes, 2010, p. 2).

Severino, o migrante personagem do poema, pode ser qualquer um de nós, em um contexto histórico diferente, porém com dificuldades que se assemelham às do trabalhador atual, como a falta de emprego, a busca por melhores condições de vida. O texto também apresenta questões como a estratificação social e a hierarquização do trabalho, entre outras temáticas que serão abordadas no decorrer da aplicação da sequência didática aqui proposta. Nesse sentido, a pesquisa adota a concepção interacionista, reconhecendo a língua como um fenômeno social. Essa concepção foi desenvolvida por Vygotsky (2010), que afirma o seguinte:

Sabemos por uma grande quantidade de pesquisas - a que no momento apenas podemos aludir - que o desenvolvimento das funções psicointelectuais superiores na criança, dessas funções especificamente humanas, formadas no decurso da história do gênero humano, é um processo absolutamente único. Podemos formular a lei fundamental deste desenvolvimento do seguinte modo: Todas as funções psicointelectuais superiores aparecem duas vezes no decurso do desenvolvimento da criança: a primeira vez, nas atividades coletivas, nas atividades sociais, ou seja, como funções interpsíquicas: a segunda, nas atividades individuais, como propriedades internas do pensamento da criança, ou seja, como funções intrapsíquicos (Vygotsky, 2010, p. 114).

Ou seja, Vygotsky (2010) acredita que o desenvolvimento do ser humano ocorre por meio de inter-relações deste com a sociedade em que vive. Desse modo, compreendendo que as interações sociais são importantes para a aprendizagem de uma linguagem e para a aprendizagem dos sujeitos, optou-se por um poema que tivesse alguma relação com os sujeitos da aprendizagem. Assim, Morte e vida Severina apresenta aspectos importantes da cultura e da caracterização não só do nordestino, mas também do trabalhador informal e formal, a exploração da mão de obra e os desafios enfrentados por Severino na busca por trabalho.

Trabalhar a literatura em sala de aula sob a perspectiva do trabalho contribui para o desenvolvimento de concepções mais amplas sobre os assuntos abordados, tendo em vista que, segundo Silva e Lima (2021), a linguagem é uma prática social e serve como elo de comunicação, isto é: "como produto da interação entre indivíduos socialmente organizados" (Silva \& Lima, 2021, p. 398).

Voltando para a questão da sequência didática aplicada, adaptada à realidade brasileira e aos objetivos almejados por esta pesquisa, é válido salientar que, conforme afirma Lopes-Rossi (2011), trabalhar os gêneros textuais de forma sistemática é 
importante, ao passo que proporciona o desenvolvimento da autonomia dos alunos no que diz respeito à leitura e à produção textual, uma vez que os expõe a situações comunicativas. Nesse sentido, a proposta de sequência didática apresentada neste trabalho contém, em seus módulos, os principais aspectos no que concerne à leitura e à compreensão do gênero poema. Seguindo o modelo proposto por Dolz e Schneuwly (2004) e incorporando outras teorias no que diz respeito ao ensino da literatura e, principalmente, do trabalho como princípio educativo, a sequência didática apresentada a seguir é composta por três fases - apresentação inicial, módulos e produção final - e tem por finalidade desenvolver uma aprendizagem a respeito dos desafios no mundo do trabalho a partir da análise do poema Morte e vida Severina, de João Cabral de Melo Neto.

\subsection{Sequência didática: desenvolvimento}

Para melhor situar a proposta de trabalho, é importante conhecer um pouco sobre o poema e seu autor, o poeta João Cabral de Melo Neto (1920-1999). Frazão (2019), que escreveu um pouco da biografia desse autor, informa que ele foi um poeta da "Geração de 45". Porém, as análises de seus poemas demonstram que ele trilhou seus próprios caminhos, iniciando com poesias de difícil compreensão e desenvolvendo, em seguida, uma poesia em que revela preocupação com aspectos formais.

De acordo com Ramos (2016), João Cabral de Melo Neto gostava de leitura, mas não gostava de poesia, por considerá-la romântica. No entanto, ao conhecer os poemas "Não sei dançar", de Manuel Bandeira, e "Noturno de Belo Horizonte", de Mário de Andrade, percebeu que poderia ser poeta sem ser sentimental. Assim, dedicou-se a esse tipo de escrita, publicando algumas obras. Dentre as mais conhecidas, está a que será objeto de estudo desta pesquisa: o poema Morte e vida Severina, elaborado para o auto de natal pernambucano.

O poema Morte e vida Severina foi escrito entre os anos de 1954 e 1955 e foi encomendado, segundo Ramos (2016), para ser um auto de natal, como mencionado anteriormente. O referido poema narra a estória de um retirante, chamado Severino, o qual sai do sertão Nordestino, mais especificamente do interior de Pernambuco, em direção a Recife. Severino faz um longo trajeto, caminhando pelas paisagens secas do Nordeste e, em seu caminho, depara-se com diversas situações, com forte presença da morte por todas as cidades por onde passa.

No entanto, este trabalho tem como proposta utilizar o poema para enfocar a problemática do mundo do trabalho, destacando principalmente os desafios enfrentados pelo retirante nordestino para conseguir um emprego. Nesse sentido, para que esse tema seja levado para a sala de aula, propõe-se a seguinte sequência didática:

A sequência didática proposta é composta por quatro momentos, cada um deles correspondente a $2 \mathrm{~h} / \mathrm{aulas}$.

\section{$1^{\text {a Etapa }}$}

\section{Aula 1: Contextualização}

A primeira etapa teve como objetivo apresentar ao aluno o conteúdo que seria trabalhando, os objetivos da pesquisa, bem como introduzir o estudo sobre o poema, apresentando o conceito desse gênero textual, bem como a contextualização da obra Morte e vida Severina e de seu autor, João Cabral de Melo Neto. Nessa primeira fase, também é solicitado ao aluno que ele responda a um questionário inicial sugerido desta forma:

\section{Questionário Inicial}

1 Você trabalha ou já trabalhou?
( ) $\operatorname{Sim}$
( ) Não

2 Você acha que a literatura pode contribuir para o enfrentamento dos desafios existentes no mundo do trabalho? Por quê?

( ) $\operatorname{Sim}($ ) Não 
3 Quais dos problemas abaixo você considera um dos mais enfrentados na busca do primeiro emprego?

( ) Não ter experiência

( ) Não ter qualificação na profissão buscada

( ) Questões relacionadas a ansiedade

( ) Nenhuma, o desemprego que é grande mesmo

( ) Outro

4 Quais das opções abaixo você considera uma característica importante para quem busca trabalho?

( ) Conhecer o mercado profissional

( ) Qualificação

( ) Conhecer os direitos e deveres trabalhistas

( ) Boa relação interpessoal

( ) Franqueza

( ) Estar informado

$5 \quad$ O que é trabalho para você?

6 No que diz respeito relações trabalhistas no decorrer da história marque a afirmativa que você concorda:

( ) Cada período histórico teve relações trabalhista conforme as necessidades da época.

( ) Ainda se tem muito a avançar no que diz respeito aos direitos trabalhistas.

( ) Os trabalhadores atuais, assim como os do passado, precisam exercer funções fixas, predeterminadas pelas empresas para se atingir determinado fim.

( ) flexibilidade, o trabalho em equipe e o conhecimento do negócio são características necessárias para o trabalhador na atualidade

$7 \quad$ Quais das afirmativas abaixo você mais se identifica?

( ) A vida profissional se define a partir do primeiro emprego.

( ) É preciso realizar ações boas e desagradáveis em qualquer emprego.

( ) As experiências de trabalho são diversas ao longo da vida até que se encontre o caminho que consideramos o certo.

( ) A maior parte das pessoas desempregadas são pessoas desqualificadas.

\section{$2^{\text {a }}$ Etapa}

\section{Aula 2: O Poema Por Vários Recursos De Expressão}

O objetivo dessa aula é apresentar de forma mais dinâmica o conteúdo do poema e demonstrar aos alunos a diversidade de gêneros textuais utilizados para apresentar a mesma obra.

Para essa aula, deve ser entregue o poema na forma escrita e disponibilizadas também as versões em vídeo, como o curta metragem do poema Morte e vida Severina criada pela Fundação Joaquim Nabuco e TV Escola ${ }^{1}$, com duração de cinquenta e cinco minutos e dezessete segundos, o filme produzido em 1981 pela TV Globo e dirigido por Walter Avancini ${ }^{2}$, a peça teatral ${ }^{3}$ e os quadrinhos criados pelo cartunista Miguel Falcão, que podem ser vistos a seguir:

\footnotetext{
${ }^{1}$ Disponível em: https://www.youtube.com/watch?v=clKnAG2Ygyw Acesso em: 25 set. 2019.

${ }^{2}$ Disponível m: https://www.youtube.com/watch?v=MthmmdJgQXY Acesso em: 25 set. 2019.

${ }^{3}$ Disponível em: https://www.youtube.com/watch?v=yfF2q6lfVSY Acesso em: 25 set. 2019.
} 
Figura 2 - Poema Morte e vida Severina ilustrado por Miguel Falcão.
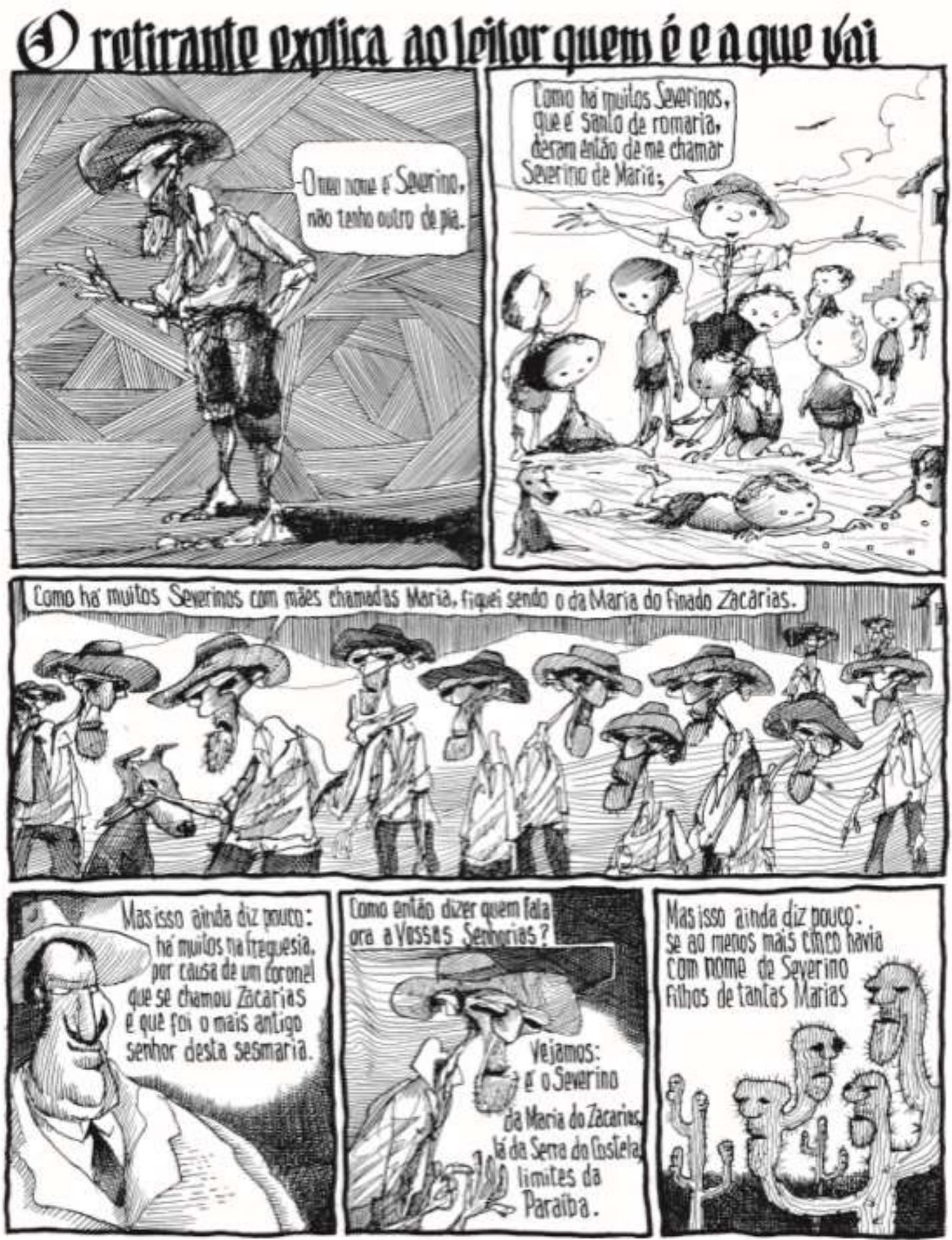

Fonte: Melo Neto (2009, p. 9).

A Figura 2 demonstra a história do poema de João Cabral de Melo Neto retratada em quadrinhos, sendo mais uma opção para que os alunos possam conhecer e ter uma leitura mais didática do conteúdo do poema. O objetivo era demonstrar as diversas possibilidades de o aluno fazer a leitura do poema, bem como oferecer condições para que buscasse a forma que considerava mais interessante para conhecer o poema. 
Após essa exposição, os alunos foram convidados a refletir sobre a diversidade de gêneros textuais existentes, discutindo as seguintes questões: 1) Que outras formas textuais você usaria para representar o assunto abordado no poema Morte e vida Severina? 2) O que o poeta quis expressar com esse poema?

\section{Aula 3: Os desafios no mundo do trabalho}

O objetivo dessa aula é discutir a problemática dos desafios do mundo do trabalho, estimulando os alunos a refletir sobre a importância da vida em sociedade e a preparação para o trabalho para o seu desenvolvimento pessoal.

Essa etapa pode ser considerada como parte fundamental nesta sequência didática, pois nela serão destacadas as questões relativas aos desafios do mundo do trabalho presentes na obra de Melo Neto (2000). A aula deve ser iniciada com explicação aos jovens acerca dos desafios que podem ser encontrados no mundo do trabalho, abordando questões como: a profissionalização, o desemprego, o trabalho autônomo, a importância do conhecimento sobre o local em que se vive e a estratificação social no mundo do trabalho.

Assim, seleciona-se alguns versos específicos, divididos conforme tópicos dispostos no próprio poema:

$1^{\circ} \mathrm{O}$ retirante explica ao leitor quem é e a que vai (Melo Nato, 2000, p. 2);

$2^{\circ}$ Cansado da viagem, o retirante pensa interrompê-la por uns instantes e procurar trabalho ali onde se encontra e dirige-se à mulher na janela que, depois, descobre tratar-se de quem se saberá vai (Melo Nato, 2000, p. 7);

$3^{\circ}$ Assiste ao enterro de um trabalhador de eito e ouve o que dizem do morto os amigos que o levaram ao cemitério vai (Melo Nato, 2000, p. 12);

$4^{\circ}$ Chegando em Recife, o retirante senta-se para descansar ao pé de um muro alto e caiado e ouve, sem ser notado, a conversa de dois coveiros vai (Melo Nato, 2000, p. 16);

Atividade 3: A partir da explicação prévia sobre os desafios do mundo do trabalho e da leitura dos trechos selecionados do poema, os alunos tiveram a opção de se dividirem em grupos para responderem as seguintes questões:

1 Qual a relação que se pode fazer entre o retirante Severino e um trabalhador do mundo atual?

2 O que você considera que o trabalho espera do profissional hoje?

3 Nos versos, a personagem da "rezadora" fala das vantagens de sua profissão e de outras semelhantes. No contexto do poema, por que essas habilidades são consideradas importantes?

4 Descreva que relações de trabalho você identifica nas falas dos coveiros.

\section{$3^{\text {a Etapa }}$}

\section{Aula 4: Produção Final}

O objetivo desse momento é avaliar os resultados do trabalho realizado nas fases anteriores. Para isso, a turma deve realizar uma produção textual com suas impressões sobre os desafios ou conflitos existentes no mundo do trabalho e as possíveis soluções. Eles expuseram suas ideias com frases curtas. Essas frases foram divididas em "problemas" e "soluções" e apresentadas neste trabalho com a análise sobre as impressões dos alunos. Além disso, deve ser respondido o mesmo questionário que foi respondido no início com o objetivo de verificar se houve mudança nas respostas.

\section{Conclusão}

Este artigo teve como objetivo apresentar uma sequência didática que pode ser utilizada por professores de literatura da EPT. Buscou-se ainda apresentar alguns conceitos importantes para a educação profissional para uma melhor compreensão sobre os princípios que fundamental e norteiam a educação profissional nos dias atuais. 
Esta pesquisa possibilitou compreender a questão do trabalho como um princípio educativo, entendendo que a educação é a base da desalienação, pois é a formação profissional articulada com a humana que vai proporcionar aos indivíduos a conscientização e a qualificação para o trabalho.

Em relação a sequência didática, observou-se que a mesma foi desenvolvida baseada nos procedimentos elaborados por Dolz et al., (2004) os quais consideram que deve haver uma apresentação inicial, um desenvolvimento e uma produção final. A mesma desenvouvel-se a partir das discussões do poema Morte e vida Severina, do poeta João Cabral de Melo Neto, pautando-se na peregrinação do personagem Severino em busca de melhores condições de vida e trabalho. Como produção final foi sugerido uma produçao textual no qual os alunos podem expor suas percepções sobre o poema. Entende-se que esse texto, além de possibilitar a exposição das impressões dos alunos, também contribuem para a escrita literária que também é trabalhada durante o percurso do trabalho.

A educação profissional e tecnológica exige dos docentes conhecimentos específicos relacionados ao ensino profissional que fundamentem sua prática. Sabe-se que a maior parte dos docentes tem formação inicial que não os prepara para uma docência na educação profissional. Assim, é importante que esses professores tenham cursos e aperfeiçoamento e/ou materiais que possam subsidiar sua prática para proporcionar ao aluno um ensino profissionalizante tão almejado pelos discentes que optam pela EPT. Nesse sentido, materiais como a sequência didática aqui apresentada podem contribuir para fomentar um pouco os materiais bibliográficos que podem ser fontes para professores e alunos.

Longe de ser uma discussão finda, esse trabalho pode ser utilizado como base para pesquisas futuras, principalmente no que diz respeito a abordagem do trabalho como princípio educativo tanto na literatura, quanto em outras áreas do saber. A mesma contribui para o preenchimento de lacunas no âmbito da educação integrada e pode ser ponto de partida para trabalhos que tem como objetivos discutir metodologias pedagógicas na educação profissional e tecnológica.

\section{Referências}

Araújo, D. L. (2013). O que é (como se faz) sequência didática? Entrepalavras, 3(1), http://www.entrepalavras.ufc.br/revista/index.ph $\mathrm{p} /$ Revista/article/view/148/181

Brocardo, R. O. \& Costa-Hübes, T. C. (2010). A elaboração do modelo didático de gênero e da sequência didática: uma perspectiva de trabalho com o gênero textual reportagem impressa em sala de aula. http://www.diaadiaeducacao.pr.gov.br/portals/pde/arquivos/ 2004-8.pdf

Ciavatta, M. (2006). A formação do cidadão produtivo emancipado. In: Frigotto, G; Ciavatta, M; Ramos, M (org.). Seminário de Pesquisa: trabalho de políticas públicas de educação: Projetos em disputa na sociedade brasileira, Rio de Janeiro, https://www.arca. fiocruz.br/bitstream/icict/26601/2/Livro\%20EPSJV\%20003620.pdf

Dolz, J; Noverraz, M. \& Schneuwly, B. (2004). Sequências didáticas para o oral e a escrita: apresentação de um procedimento. In: Schneuwly, Brenard; Dolz, Joaquim (org.). Gêneros orais e escritos na escola. Mercado de Letras, 81-108.

Figaro, R. (2008). O mundo do trabalho e as organizações: abordagens discursivas de diferentes significados. ORGANICOM, 5(9), http://www.eca.usp.br/departam/crp/cursos/posgrad/gestcorp/organicom/re_vista9/90.pdf

Fischer, M. C. B. \& Franzoi, N. L. (2009). Formação humana e educação profissional: diálogos possíveis. Educação, Sociedade e Cidadania, n 29, https://www.fpce.up.pt/ciie/revistaesc/ESC29/29Clara FNairaF.pdf

Frazão, D. (2019). Biografia de João Cabral de Melo Neto. E-Biografia, https://www.ebiografia.com/joao_cabral_de_melo_neto/

Frigotto, G. (2002). Trabalho, Conhecimento, Consciência e a Educação do Trabalhador: Impasses Teóricos e Práticos. In: Gomez, C. M. et al. Trabalho e Conhecimento: Dilemas na Educação do Trabalhador. São Paulo: Cortez.

Gil, A. C. Como elaborar projetos de pesquisa. (5a ed.), Atlas.

Goldenberg, M. (2009). A arte de pesquisar: como fazer pesquisa qualitativa em Ciências Sociais. Record.

Gramsci, A. (2001). Cadernos do cárcere. Tradução de Carlos Nelson Coutinho, 2, Civilização Brasileira: https://netmundi.org/home/wpcontent/uploads/2019/03/Antonio-Gramsci-Cadernos-do-c\%c3\%a1rcere-v.-2.pdf

Lopes-Rossi, M. A. G. (2011). Gêneros discursivos no ensino de leitura e produção de textos. In: Karwoski, Acir Mário; Gaydeczka, Beatriz; Brito, Karim Siebeneicher. (org.). Gêneros textuais: reflexões e ensino. (4a ed.), Parábola Editorial. 
Research, Society and Development, v. 10, n. 17, e136101722798, 2021

(CC BY 4.0) | ISSN 2525-3409 | DOI: http://dx.doi.org/10.33448/rsd-v10i17.22798

Maciel, A. C. (2018). Marx e a politecnia, ou: do princípio educativo ao princípio pedagógico. Revista Exitus, Santarém/PA, 8(2), https://dialnet.unirioja.es/servlet/articulo?codigo=6399936

Medeiros Neta, O. M; Assis, S. M. \& Lima, A. C. S. (2016). O trabalho como princípio educativo: uma possibilidade de superação da dualidade educacional no ensino médio integrado. Revista Ensino Interdisciplinar, 2(5), https://repositorio.ufrn.br/jspui/bitstream/123456789/23170/1/ OTrabalhoComoPr\%C3\%ADncipio_2016.pdf

Melo Neto, J.C. (2000). Morte e vida Severina e outros poemas para vozes. (4a ed.), Nova Fronteira.

Oliveira Neto, N. A. de; Azevedo, R. O. M. \& Aride, P. H. R. (2018). Trabalho como princípio educativo: definição do conceito e sua relação com o capitalismo. Educação Profissional e Tecnológica em Revista, 2(2), https://ojs.ifes.edu.br/index.php/ept/article/view/387/346

Pacheco, E. (2015). Fundamentos político-pedagógicos dos institutos federais: diretrizes para uma educação profissional e tecnológica transformadora. / Eliezer Pacheco.: IFRN, https://memoria.ifrn.edu.br/bitstream/handle/1044/1018/Fundamentos\%20Poli\%20tico-Pedago\%20gicos\%20dos\%20Institutos\%2 0Federais\%20-\%20Ebook.pdf?sequence $=1$

Ramos, A. C. R. C. (2016). Caminhos do sertão em morte e vida Severina: diálogo entre a geografia e a literatura. 2016. 94f. Dissertação (Mestrado em Educação). Universidade Nove de Julho - UNINOVE, S http://bibliotecatede.uninove.br/bitstream/tede/1396/2/Ana\%20Carolina\%2 0Robles\%20De\%20Cara\%20Ramos.pdf

Saviani, D. (1994). O trabalho como princípio educativo frente às novas tecnologias. In: Novas tecnologias, trabalho e educação. Vozes.

Silva, E. .B. \& Lima, S. C. (2021). Vozes Que Se Integram No Ensino Médio Da Educação Profissional: Uma Sequência Didática Para A Escrita De Resenha Da Obra A Revolução Dos Bichos. Revista Humanidades E Inovação, 8(53), HTTPS://REVISTA.UNITINS.BR/INDEX.PHP/HUMANIDA DESEINOVACAO/ARTICLE/VIEW/5912

Sobral, K. M. et al. (2016). Gramsci e o trabalho como princípio educativo: escola unitária e a construção da nova sociedade. Revista Histedbr On-line, n. 70, https://www.researchgate.net/publication/316901275_Gramsci_e_o_trabalho_como_principio_educativo_escola_unitaria_e_a_construcao_da_nova_sociedade

Souza, F. C. S. Ensino médio integrado à educação profissional: expansão e desafio para os institutos federais. In: Encontro estadual de didática e prática de ensino - EDIPE, 17, 2014, Fortaleza. Anais [...]. Fortaleza: Universidade Estadual do Ceará, http://www.uece.br/endipe2014/ebooks/livro3/219\%20ENSINO \%20M\%C3\%89DIO\%20INTEGRADO \%20\%C3\%80\%20EDUCA\%C3\%87\%C3\%83O\%20PROFISSIONAL\%20EXPANS\%C3\%83O \%20E\%20DESAFIO $\% 20$ PARA\%20OS\%20INSTITUTOS\%20FEDERAIS.pdf

Tavares, A. \& Corso, A. M. (2015). Trabalho e escola: relações que permeiam a escolarização do aluno do ensino médio noturno. In: Congresso Nacional De Educação - EDUCERE, 21., Curitiba. Anais [...]. Curitiba: Pontifícia Universidade Católica do Paraná, 2015. https://educere.bruc.com.br/arquivo/pdf2015/18414_9657.pdf

Venzel, F. C. B. S. (2007). Integração entre educação e trabalho: uma reflexão sobre a prática docente nos cursos de Ensino Médio Integrado a Educação Profissional. Revista Gestão Escolar, http://www.gestaoescolar.diaadia.pr.gov.br/arquivos/File/producoes_pde/artigo_francisca _carmo_barbosa_silveira_venzel.pdf

Vygotsky, L. S. (2010). Aprendizagem e desenvolvimento intelectual na idade escolar. In: Vigotskii, L. S.; Luria, A. R.; Leontiev, A. N. (org.). Linguagem, Desenvolvimento e Aprendizagem. tradução de: Maria da Pena Villa lobos. (11a ed.), Ícone. (Coleção Educação Crítica). 